Editorial

Pensar en Movimiento:

Revista de Ciencias del Ejercicio y la Salud

EISSN 1659-4436

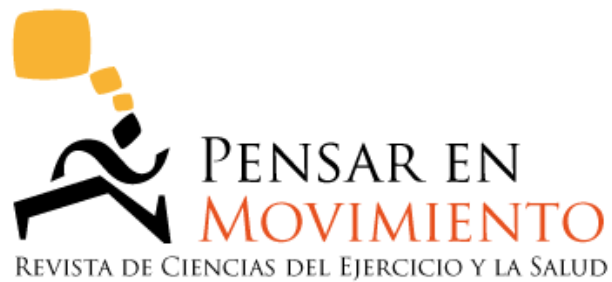

Vol. 12, No. 2, pp. 18- 25

\title{
PUBLICAÇÃO MULTILÍNGUE COMO FERRAMENTA LEGÍTIMA PARA AUMENTAR O ACESSO A CIÊNCIA \\ (Versão traduzida em Português) ${ }^{1}$
}

\author{
Luis Fernando Aragón Vargas, Ph.D. ${ }^{1}$; FACSM \& Orlando Laitano, Ph.D. ${ }^{2}$ \\ ${ }^{1}$ LUIS.ARAGON@ucr.ac.cr, Escuela de Educación Física y Deportes, Universidad de \\ Costa Rica, Costa Rica \\ ²orlando.laitano@gmail.com, Universidade Federal do Vale do São Francisco, Brasil
}

Manuscrito publicado: $12 / 12 / 2014$

doi: http://dx.doi.org/10.15517/pensarmov.v12i2.17585

\section{RESUMO}

Aragón-Vargas, L.F. (2014). Publicação multilíngue como ferramenta legítima para aumentar o acesso a ciência. Pensar en Movimiento: Revista de Ciencias del Ejercicio y la Salud, 12 (2), 18-25. Duplicar uma publicação, incluindo a submissão ou publicação do mesmo manuscrito em dois ou mais idiomas, é considerado conduta científica inadequada. Entretanto, realizar publicação multilíngue de maneira apropriada tem sido uma exceção difícil de gerenciar como parte do processo normal de publicação científica. Enquanto uma publicação em segundo ou terceiro idioma não deve receber o mesmo crédito de uma publicação original, esta não deve ser punida. Desde que observações apropriadas e etapas preliminares sejam respeitadas, esta modalidade deve ser altamente estimulada, pois aumentará a comunicação científica e poderá reduzir a lacuna de conhecimento no mundo inteiro. Tipos diferentes de publicações multilíngues serão apresentadas e algumas orientações básicas são oferecidas para a publicação adequada do mesmo artigo em múltiplos idiomas.

Palavras chave: Publicação duplicada, ética das ciências, ética em publicação, tradução

De acordo com o International Committee of Medical Journal Editors (ICMJE), a submissão do "mesmo manuscrito, no mesmo ou diferente idioma, simultaneamente em mais de um periódico" é considerada conduta inadequada (International Committee of Medical Journal Editors, 2014, Tradução livre). Existem razões relevantes e pertinentes para essa norma, mas nós gostaríamos de apresentar uma análise racional e algumas

\footnotetext{
${ }^{1}$ Disponível em espanhol e Inglês
} 
orientações para editores de periódicos científicos sobre a publicação do mesmo manuscrito em dois ou mais idiomas, uma prática que poderia melhorar a comunicação científica e não deveria ser considerada uma conduta inadequada. Este artigo foi inspirado por um editorial escrito por Zhang (2013).

Um argumento central para a publicação multilíngue é o fato de que a ciência de países secundários precisa ser mais visível. Muitos artigos têm discutido ciência escondida ou "perdida": pesquisas valiosas em línguas secundárias como o Espanhol ou o Português que normalmente são ignoradas em revisões sistemáticas e sequer são lidas por cientistas (Gibbs, 1995; Stolerman \& Stenius, 2008; Williams, Bórquez, \& Basáñez, 2008). Embora o Inglês seja o idioma para comunicação científica, o conhecimento não deve possuir um único idioma.

\section{Publicação bilíngue}

A publicação multilíngue de artigos científicos possui formas diferentes. Por exemplo, o mesmo artigo pode ser publicado em dois ou mais idiomas no mesmo periódico, mas não existem orientações claras sobre como proceder neste caso. Alguns periódicos têm publicado um único artigo (com um único digital object identification - DOI) em dois idiomas, lado a lado no mesmo arquivo eletrônico ou cópia impressa (cf. Jeukendrup, 2013). Isso pode ser chamado de publicação bilíngue, mas possui limitações porque o idioma secundário não está visível nas ferramentas de busca e o DOI leva apenas para a informação no idioma primário. Devido a essas limitações, os leitores que poderiam se beneficiar pela disponibilidade da informação em seu próprio idioma, sequer sabem da sua existência. Além disso, enquanto a citação pode ser considerada simples, não há transparência completa, pois a versão do idioma usado na submissão e no processo de revisão normalmente não é revelada e não corresponde ao idioma primário do periódico.

\section{Publicação multilíngue simultânea}

Outros periódicos disponibilizam o mesmo artigo em dois ou mais idiomas, simultaneamente mas como arquivos eletrônicos separados, usando o mesmo DOI (cf. Angelo, Leite, \& Castilho, 2011), aqui referido como publicação multilíngue simultânea. Este serviço é muito útil para os leitores que sabem onde buscar, mas novamente, pode não estar visível nas ferramentas de busca. O uso de um único DOI é opcional; a opção é surpreendente, pois os principais softwares de administração de periódicos como o Open Journal System atribui URLs separados para diferentes versões de idiomas do mesmo artigo, e o CrossRef fornece uma forma para usar um DOI separado para cada idioma (CrossRef, 2014).

A publicação multilíngue simultânea desempenha uma função muito importante na comunicação científica, como recentemente sugerido por Salager-Meyer (2014). Atualmente, em reconhecimento a qualidade do trabalho realizado por cientistas que não falam Inglês, muitos dos grandes periódicos oferecem serviços de tradução profissional (com custo), para viabilizar a publicação em Inglês. Quando esses autores optam por -19 - 
fazer isso, ao invés de usarem sua própria língua, eles estão, na prática, fechando as portas para os seus colegas que não terão acesso a informação. Esta restrição pode ser tão relevante quanto aquela previamente imposta pelos periódicos pagos, uma séria limitação que vem sendo superada graças ao movimento Open Access, com seus baixos custos, depósito obrigatório em repositórios públicos e outras mudanças no modelo de publicação. A publicação multilíngue simultânea é altamente recomendada, pois atinge uma população que normalmente fornece os recursos e até mesmo participam como voluntários nos estudos. Ela também faz com que a informação científica seja prontamente disponível para cientistas locais ou regionais em seus idiomas nativos, enquanto supre a necessidade dos autores em tornar seu trabalho visível para o resto do mundo.

Quando um periódico decide publicar o mesmo manuscrito em dois ou mais idiomas, ele está fornecendo um serviço importante e evitando muitos - se não todos - os problemas causados pela publicação duplicada, como indicado por Alfonso et al. (Alfonso, Bermejo, \& Segovia, 2005). Apenas um processo de revisão pelos pares é realizado, existe transparência, e o periódico pode decidir se tem o espaço e os recursos necessários para fazer isso sem prejudicar os artigos convencionais. O objetivo atual é, no entanto, realizar melhoras importantes neste sistema. Primeiro, tanto as publicações bilíngues quanto as publicações bilíngues simultâneas devem incluir uma observação, de preferência próxima da data de submissão do manuscrito, sobre o idioma usado para a submissão e revisão. Segundo, um sistema mais eficiente precisa ser implementado para permitir diferentes citações em cada versão de idioma, pois haverá sempre diferenças que podem causar confusões; a citação da versão lida pelos autores é recomendada. Terceiro, para tornar a versão em idioma secundário visível e amplamente acessível, a separação da identificação digital do objeto e/ou a indexação é recomendável, seguindo as instruções do CrossRef (2014). O fato de o artigo estar disponível em outros idiomas deve estar explícito na primeira página e nos metadados.

\section{Tradução de artigos previamente publicados}

Uma modalidade distinta é a tradução de um artigo publicado em dois ou mais idiomas em diferentes periódicos. Aqui denominado publicação multilíngue sequencial, esta é considerada e recomendada pelo International Committee of Medical Journal Editors (2014) se o objetivo é atingir ampla audiência com informação relevante. Muitos periódicos possuem normas e políticas de tradução para diferentes organizações mundiais (cf. Alfonso et al., 2005), mas apenas recentemente as normas sobre como publicar artigos em idiomas secundários (International Committee of Medical Journal Editors, 2014) ou traduções para o Inglês (The European Association of Science Editors, 2014) foram publicadas, este último é de natureza mais técnica e não se refere especificamente a manuscritos publicados previamente.

Organizações como o American College of Sports Medicine comissionam a tradução oficial dos seus posicionamentos em diferentes idiomas (cf. American College of 
Sports Medicine, 2014), mas os documentos resultantes normalmente não são publicados em periódicos científicos e tipicamente só ficam disponíveis para membros da organização ou visitantes do seu website. As traduções são consideradas um serviço para visitantes, e não publicações. Enquanto publicações formais deste tipo de artigo seriam altamente recomendadas, deveria existir um intervalo previamente acordado entre a publicação original e a secundária, para ganhar destaque em relação a primeira (International Committee of Medical Journal Editors, 2014).

O trabalho intelectual envolvido nessas traduções normalmente não é levado em consideração nos créditos obtidos, o que gera uma questão interessante sobre autoria: se um artigo traduzido (secundário) for publicado, os autores devem ser os mesmos do trabalho original, ou o cientista que traduziu o artigo, com a observação e autorização apropriada, seria o autor do trabalho secundário? A resposta não é tão óbvia quanto parece, pois alguns ou todos os autores originais podem questionar ao assumir a responsabilidade por um artigo em um idioma que eles não entendem! Existem outras questões para serem consideradas: o editor do periódico da publicação secundária pode considerar desnecessário realizar um processo de revisão pelos pares convencional, ou pode decidir contratar um profissional para garantir a precisão da tradução. Essas e outras questões variam dependendo da ordem dos idiomas na sequência da publicação.

A publicação de artigos em Inglês traduzidos em idiomas secundários não é incomum. Como exemplo na área da ciência do exercício, o Editorial Biosystem da Argentina publica artigos de pesquisas internacionais em suas versões completas e traduzidos profissionalmente desde 1997, com o objetivo de tornar o trabalho original disponível para cientistas e profissionais que falam Espanhol. Autores e editoras dos trabalhos originais em Inglês devem fornecer as permissões apropriadas para este tipo de iniciativa, pois a publicação em idioma secundário alcançará diferentes audiências, aumentando a disseminação do conhecimento e assim tornando mais universal, de acordo com as recomendações de Salager-Meyer para melhorar a qualidade da ciência a qual ele chama de periférica (Salager-Meyer, 2008).

Por outro lado, periódicos de grande impacto podem considerar a publicação da tradução em Inglês de artigos que já foram publicados em outras línguas, mas é altamente improvável. O modelo seria mais suspeito de publicação duplicada, e os autores precisariam justificar por que a submissão não foi realizada em Inglês originalmente. Isso é um problema, pois muitas pessoas no mundo compartilham da experiência do Professor Gilson Volpato (uma autoridade em publicação científica no Brasil) que destaca o valor da publicação multilíngue para não-cientistas e especialistas que atuam exclusivamente no campo da prática. Ele diz: "Eu conheci trabalhos interessantes de pesquisadores japoneses porque um israelense traduziu os artigos para o Inglês, em 1977" (comunicação pessoal, 2014). De qualquer forma, no modelo atual, nenhum periódico de grande impacto irá considerar uma publicação secundária. Isto abre uma oportunidade importante para periódicos periféricos, os quais devem não apenas fornecer os metadados e resumo em Inglês, mas devem implementar publicação multilíngue simultânea do manuscrito completo. Estes periódicos também podem 
considerar a publicação do manuscrito previamente publicado em seu idioma primário como publicação secundária traduzida para o Inglês.

\section{Transparência, observância e pendências}

A publicação legítima de um artigo traduzido não deve apenas seguir normas estritas de propriedade intelectual, mas também deve estar de acordo com critérios pré estabelecidos por questões de transparência, principalmente no caso de publicação sequencial: permissões devem ser obtidas por escrito da editora e todos os autores do artigo original; a natureza do artigo traduzido deve ser destacada na submissão ao periódico secundário; o autor deve explicar o motivo para a tradução no corpo do artigo; o periódico deve destacar informações relevantes no titulo do artigo e nos metadados; o artigo original deve ser devidamente citado (International Committee of Medical Journal Editors, 2014; Zhang, 2013).

Uma questão importante que permanece por ser esclarecida é o manejo do mérito acadêmico; pois este não é trabalho original, uma publicação (traduzida) secundária não deve contar, ou deveria ter peso muito diferente (ela tem uma contribuição importante para o corpo de conhecimento em idioma secundário), quando avaliações quantitativas são realizadas por autores ou instituições específicas (Zhang 2013). Isto requer políticas específicas e algoritmos a serem desenvolvidos, mas os elementos de transparência nos parágrafos prévios ajudarão na sua implementação.

\section{Comentários finais}

Leitores são estimulados a considerarem o presente artigo como um exemplo: se publicado apenas em Inglês, autores de idioma secundário não encontrariam facilmente informação sobre essas importantes tendências nas publicações, as quais podem ter um impacto direto em seus trabalhos. Por outro lado, se publicado apenas em Espanhol ou Português, os editores de muitos periódicos primários seriam afastados do debate. Nós acreditamos que este editorial estimulará mais periódicos periféricos a incluírem publicações multilíngues. Além disso, autores estão convidados a traduzirem este editorial, respeitando a licença de atribuição, em outras línguas secundárias.

Até pouco tempo, publicações multilíngues eram uma exceção difícil de gerenciar ao invés de serem parte normal do processo de publicação científica. Enquanto a publicação em duas ou mais línguas não deve receber o mesmo peso de uma publicação original, ela não deve ser punida. Desde que observações apropriadas e etapas preliminares sejam realizadas, ela deve ser altamente estimuladas, pois aumenta a comunicação científica e pode reduzir as lacunas de conhecimento no mundo inteiro. Uma tentativa de classificar diferentes tipos de publicações multilíngues foi realizada (ver tabela 1), e poucas recomendações têm sido apresentadas para servir como documento de trabalho para a publicação de orientações necessárias. 


\section{Tabela 1.}

Proposta de classificação de processos redundantes de publicação em dois ou mais idiomas.

\begin{tabular}{|c|c|c|c|c|}
\hline & $\mathrm{ICMJE}^{\mathrm{a}}$ & Springer $^{b}$ & Elsevier $^{c}$ & Comentários/recomendação \\
\hline Submissão duplicada & $\begin{array}{l}\text { Condenada. Múltiplos idiomas } \\
\text { não } \\
\text { explicitamente. }\end{array}$ & $\begin{array}{ll}\text { Condenada. Múltiplos idiomas } \\
\text { não } & \text { mencionados } \\
\text { explicitamente. } & \end{array}$ & $\begin{array}{ll}\text { Condenada. Múltiplos idiomas } \\
\text { não } & \text { mencionados } \\
\text { explicitamente. } & \end{array}$ & $\begin{array}{l}\text { Conduta científica } \\
\text { indadequada. } \\
\text { Injustificável. }\end{array}$ \\
\hline Publicação duplicada & $\begin{array}{l}\text { Condenada. Múltiplos idiomas } \\
\text { apresentados como } \\
\text { categorias separadas (ver } \\
\text { Publicações Secundárias). }\end{array}$ & $\begin{array}{l}\text { Condenada, exceto quando } \\
\text { permitido ou notificado. }\end{array}$ & $\begin{array}{l}\text { Condenada. Múltiplos idiomas } \\
\text { discutidos sob submissão } \\
\text { duplicada abaixo. }\end{array}$ & $\begin{array}{l}\text { Má conduta científica. } \\
\text { Deve ser evitada seguindo } \\
\text { claramente } \\
\text { estabelecidos. }\end{array}$ \\
\hline $\begin{array}{l}\text { Publicação bilíngue (Refere- } \\
\text { se a uma única publicação de } \\
\text { um artigo em dois idiomas, } \\
\text { lado a lado na mesma } \\
\text { página). }\end{array}$ & Não mencionado. & Não mencionado. & Não mencionado. & $\begin{array}{l}\text { Claramente NÃO se trata de } \\
\text { conduta inadequada. } \\
\text { Apenas um idioma estará } \\
\text { visível nos motores de busca } \\
\text { e acessado pelo DOI. }\end{array}$ \\
\hline $\begin{array}{l}\text { Publicação multilíngue } \\
\text { sequencial (Refere-se a } \\
\text { publicação de um artigo em } \\
\text { dois ou mais idiomas em } \\
\text { diferentes periódicos). }\end{array}$ & $\begin{array}{l}\text { Aceitável como Publicações } \\
\text { Secundárias. Considerada } \\
\text { justificável e benéfica, } \\
\text { particularmente se o objetivo } \\
\text { for atingir uma ampla } \\
\text { audiência com informação } \\
\text { relevante. Sujeito a critérios } \\
\text { condicionais (ver a). }\end{array}$ & $\begin{array}{l}\text { Abre a possibilidade com } \\
\text { permissão ou notificação. } \\
\text { Não é explicitamente } \\
\text { estimulado. }\end{array}$ & $\begin{array}{l}\text { Opcional, mas seguindo } \\
\text { claramente critérios do tipo de } \\
\text { submissão (ver c c). Não } \\
\text { recomendada explicitamente. }\end{array}$ & $\begin{array}{l}\text { Recomendada, especialmente } \\
\text { de idiomas primários para } \\
\text { secundarios. } \\
\text { Necessita de transparência. } \\
\text { Indexaçãorarara separada } \\
\text { recomendada (atualmente } \\
\text { não é o caso no PUBMED). } \\
\text { Separar o DOI sem dúvidas. }\end{array}$ \\
\hline $\begin{array}{l}\text { Publicação multilíngue } \\
\text { simultânea (Refere-se a } \\
\text { publicação de um artigo em } \\
\text { dois ou mais idiomas como } \\
\text { arquivos separados em um } \\
\text { mesmo periódico). }\end{array}$ & $\begin{array}{l}\text { Um exemplo é brevemente } \\
\text { mencionado com algumas } \\
\text { características especiais. }\end{array}$ & Não mencionado. & Não mencionado. & $\begin{array}{l}\text { Recomendada. } \\
\text { Necessita de transparência. } \\
\text { Indexação separada } \\
\text { recomendada (atualmente } \\
\text { não é o caso no PUBMED). } \\
\text { Separar o DOI seria mais } \\
\text { adequado para cada versão } \\
\text { para melhorar a visibilidade e } \\
\text { citação adequada. }\end{array}$ \\
\hline
\end{tabular}

\footnotetext{
a Elaborado de "Overlapping publications" por International Committee of Medical Journal Editors, 2014.

${ }^{b}$ Elaborado de "Publishing ethics for journals. A guide for Editors-in-Chief, Associate and Managing editors" por Springer, $\underline{\text { n.d. }}$

c Elaborado de "Identify 3. What identifies a case in this area?" por Elsevier, 2014.
} 


\section{Referências}

American College Sports Medicine. (2014). Translated Position Stands. Recuperado de: http://www.acsm.org/about-acsm/international-outreach/translated-position-stands

Alfonso, F., Bermejo, J., \& Segovia, J. (May, 2005). Duplicate or Redundant Publication: Can We Afford It? Revista Española de Cardiología (English Edition), 58(5), 601604. doi: http://dx.doi.org/10.1016/S1885-5857(06)60739-1

Angelo, M., Leite, M. M. J., \& Castilho, V. (2011). Journal networking in nursing: a challenge to be shared. Revista Da Escola de Enfermagem Da USP, 45(6), 12791280. doi: http://dx.doi.org/10.1590/S0080-62342011000600001

CrossRef. (n.d.). Assigning DOIs to translations. Recuperado de: http://help.crossref.org/translations

Elsevier. (2014). Identify 3. What identifies a case in this area? Recuperado de: http://www.elsevier.com/editors/perk/multiple,-duplicate,--concurrentpublicationsimultaneous-submission/identify-3

Gibbs, W. (August, 1995). Lost Science in the Third World. Scientific American, 273, 9299. Recuperado de: http://www.scientificamerican.com/article/lost-science-in-thethird-world/

International Committee of Medical Journal Editors. (2014). Overlapping publications. Recuperado de: http://www.icmje.org/recommendations/browse/publishing-andeditorial-issues/overlapping-publications.html

Jeukendrup, A. (2013). Los carbohidratos durante el ejercicio: la investigación de los últimos 10 años. Nuevas recomendaciones. Apunts, (113), 7-22. doi: http://dx.doi.org/10.5672/apunts.2014-0983.es.(2013/3).113.00

Salager-Meyer, F. (2008). Scientific publishing in developing countries: Challenges for the future. Journal of English for Academic Purposes, 7(2), 121-132. doi: http://dx.doi.org/10.1016/j.jeap.2008.03.009

Salager-Meyer, F. (2014). Writing and publishing in peripheral scholarly journals: How to enhance the global influence of multilingual scholars? Journal of English for Academic Purposes, 13, 78-82. doi: http://dx.doi.org/10.1016/j.jeap.2013.11.003

Stolerman, I. P., \& Stenius, K. (January, 2008). The language barrier and institutional provincialism in science. Drug and Alcohol Dependence, 92(1-2), 1-2. doi: http://dx.doi.org/10.1016/j.drugalcdep.2007.07.010

Springer. (n.d.). Publishing Ethics for Journals. A guide for Editors-in-Chief, Associate and Managing editors. Recuperado de: http://www.springer.com/gp/authorseditors/editors\#c4176 
The European Association of Science Editors. (2014). EASE Guidelines for Authors and Translators of Scientific Articles to be Published in English. Recuperado de: http://www.ease.org.uk/publications/author-guidelines

Williams, J. R., Bórquez, A., \& Basáñez, M.-G. (2008). Hispanic Latin America, Spain and the Spanish-speaking Caribbean: A rich source of reference material for public health, epidemiology and tropical medicine. Emerging Themes in Epidemiology, 5(1), 17. doi: http://dx.doi.org/10.1186/1742-7622-5-17

Zhang, Y. (2013). Bilingual (multilingual) publications and duplicate publications: for or against? Journal of Zhejiang University-SCIENCE A, 14(9), 687-690. doi: http://dx.doi.org/10.1631/jzus.A1300272 